\title{
Experience, Behavior, and Action in Crisis Situations: A Literature Review
}

\author{
Janika Saretzki \\ ERC Experience Research \& Consulting, Austria \\ Jürgen Pretsch \\ Ekaterina Pretsch
}

\section{Abstract}

This paper presents an initial literature review of human experience, behavior, and action in crises, disasters, and threat scenarios. Crisis scenarios under the sign of partly strategic terrorism represent a dominant trend in the observation of global transformations. In the context of a generally necessary understanding concerning both physical and psychological processes during the confrontation with specific threat scenarios, both previous and future psychological and social science studies are of great importance. Regarding the acute and chronic psychological, physical, and even social consequences of specific threat scenarios, the databases PSYNDEX, PsycARTICELS, and PTSDpubs (formerly PILOTS) were accessed. Numerous publications were extracted and summarized in the following. Despite the widespread and frequently used term terrorism, this designation definition has not been uniformly generalized to date. The psychological consequences of such stressful situations are often only addressed concerning the groups of people directly affected and limited to post-traumatic stress syndromes' development. However, theories and approaches must be emphasized, dedicated to the human reaction pattern in threat scenarios, to uncover specific behavioral patterns in the confrontation with one's vulnerability. Thus, the defense of one's values and norms in the sense of the Terror Management Theory (TMT) is one of the fundamental reactions of directly and indirectly affected groups of people, which is accompanied by corresponding physiological processes and also affective states. The consideration of individual reaction patterns due to increased sensitivity concerning diverse threat scenarios also represents a thoroughly critical approach since these patterns of experience, behavior, and action can lead to an impairment of the overall social coexistence. Previous theories and approaches in the context of psychological and social science disaster research make it clear that the experience, behavior, and action both before, during, and after various threat events require more specific consideration. The distinction between persons directly and indirectly affected by particular 
circumstances also appears necessary and should be considered in future research approaches, focusing on critical infrastructures.

Keywords: review paper, disaster research, terror management theory, terror salience

Introduction. In the course of increasing national growth and the associated prosperity of the population, which can be attributed to both technological and economic development (Broadberry \& Wallis, 2017), the existence of functioning supply infrastructures must be emphasized (Besley et al., 2013). While these partly large and highly complex networks contribute to an increased social performance, they can also raise these structures' vulnerability (Lauwe \& Riegel, 2008). Dangerous or threatening situations under the sign of partly strategic terrorism represent a dominant trend in observing global transformations (Thiele, 2009). This development can be confirmed above all by authorities and organizations with security tasks: institutions that are entrusted with the defense against internal threats and form the essential elements for the protection of the population alongside military structures, through an increased emergence of specific operational incidents with a focus on partly religiously-motivated terrorist activities (Homer-Dixon, 2002; Juergensmeyer, 2017; Kressel, 2008).

Since both the theoretical foundation and the development of sufficient (practical) concepts and guidelines concerning human experience, behavior, and action in threat scenarios are not yet complete, we undertook a review of the existing literature and theoretical framework concepts. Therefore, the aim of this literature review is (a) to provide an overview of previous findings concerning individual patterns of experience, behavior, and action in threat scenarios, (b) to possibly distinguish between both the affected civilian population and the operational organizations confronted with specific active events, and (c) to be able to develop generalizable concepts that contribute to a total gain in knowledge in the course of social science crisis and disaster research.

Background. The present review represents a first attempt to summarize previous findings regarding the direct and indirect social, mental, and partly economic effects and consequences of terrorist threat scenarios. Thus, the primary research questions refer to the sociological and psychological outcomes and basic approaches and views regarding terrorist attacks and general threat situations.

Due to the constant and partly increasing topicality of the subject area, future studies and literature reviews adapted to the respective time frame will also be necessary to provide suitable measures and approaches in dealing with possible scenarios.

Aims. The study aimed to provide an overview of previous findings concerning experience, behavior, and action in crisis and terror situations. Mass psychological models should subsequently be made possible by collecting and processing relevant aspects of stress's social and individual experience. 


\section{Search Methods}

Method. The basis of the present work is formed by numerous publications, which can be found in the databases PSYNDEX, PsycARTICELS, and PTSDpubs (formerly PILOTS) about the acute experience, behavior, and action, but also to the consequences of various threat and terror scenarios.

The period of the considered publications ranges from 1986 to 2020.

Research. The databases PSYNDEX, PsycARTICELS, and PTSDpubs, which are focused explicitly on psychological-social science findings and analysis, were searched using the keywords "terror," "terrorism," and "threat scenarios." These words were supplemented by the keywords "psychological effects" and "societal consequences," respectively, thereby extracting many different findings. The research papers were limited from 1986 to 2020 to present classical and current approaches, starting points, and conclusions. Furthermore, only those studies were considered that focused on human experience, behavior, and action in the context of the described scenarios. Finally, the search was specified by the keywords "terror salience," "coping behavior," and "terror management theory." These terms were taken from the keywords of the articles deemed relevant. We also searched reference lists of reviewed articles for appropriate citations. A total of $\mathrm{N}=35$ complete papers were included in the more specific considerations, and each scholarly scientific paper was independently examined concerning the following questions: How are the key terms "terrorism" or even "threat scenarios" defined? In what context were the events mentioned above considered? Where was the focus placed in terms of the impact and consequences of said events? What sample was studied? What research method was used? What insights can the results provide concerning experiencing, behaving, and acting in threat scenarios?

The papers on which this review is based used both quantitative and, in some cases, qualitative methods. Qualitative methods are relevant in the context of the chosen topic area. They involve descriptions and interpretations of human experience and, thus, contribute to a holistic picture in the study of social and human subject areas (Creswell, 1989).

Criteria for exclusion. Various studies were excluded from the final review. Non-researchbased papers were excluded, but in some cases, inspired discussing the theoretical frameworks of relevant topic areas. Study papers that considered the consequences of terrorism and other threat scenarios to be only incidental or focused solely on the economic implications of these were also excluded. Also, physical (long-term) consequences of directly or indirectly affected persons should not be focussed on and excluded studies that put these into their focus of consideration. 


\section{Results}

Overall, three temporal perspectives characterize the previous studies and closer observations regarding the psychological, physiological, and sociological aspects and consequences of various threat events: before, during, and after specific scenarios. These temporal approaches are characterized by particular methods and theories, which will be considered in an overview below (see Figure 1).

It should be noted that the societal aspects in the context of diverse threat scenarios must often be understood as a consequence of individual behaviors and are, therefore, definitely included in the following findings despite not always being explicitly emphasized.

An essential component of previous research approaches to various threat scenarios is the examination of the economic consequences. Numerous authors have shown, for example, that falling consumer spending, changed political opinions, and severe slumps in the financial markets can be observed immediately after terrorist attacks (Lerner et al., 2003). Although these economic aspects represent a thoroughly necessary approach, especially in economic psychology, they are not considered in greater detail in the present review. Also, due to the focused psychological aspects, the physiological models as the basis of specific findings shall only serve as a brief introduction to conclude the results that now follow.

\section{Figure 1}

Time perspectives about the individual, social and economic aspects of threat scenarios
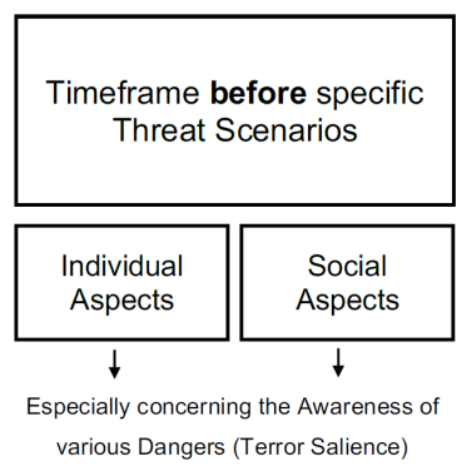

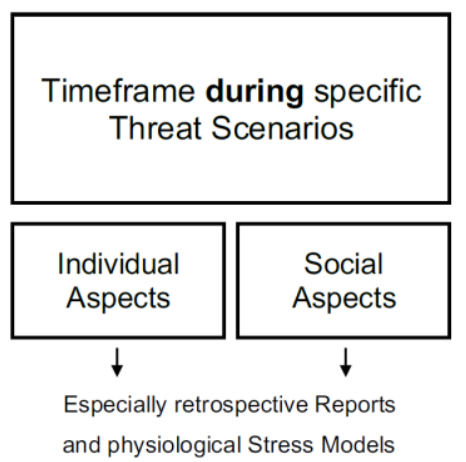

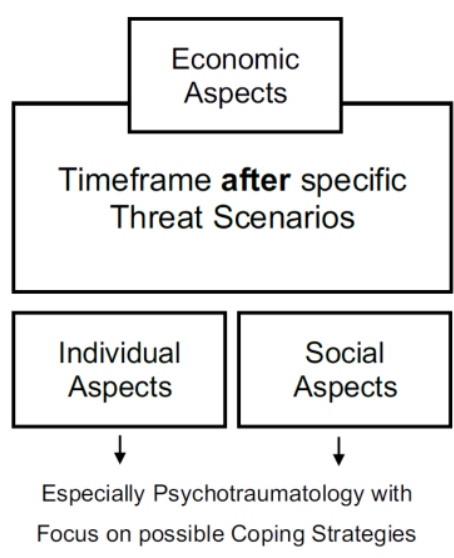

Note. The economic consequences of specific threat scenarios should be noted, but not the focus of this overview paper.

International and, in part, strategic terrorism is considered one of the most significant challenges of the modern world. Hegemann and Kahl (2018) define terrorism as a calculated use or threat of violence to generate fear and, thus, pursue politically, religiously, or ideologically motivated goals. A primary characteristic of terrorism often emphasized in numerous other definitions (and included in this definition now briefly elaborated) is the 
existing oppression of groups of people to achieve specific goals (Hoffmann, 2011). Despite the numerous attempts, however, it must be noted that so far, there is no internationally accepted and, thus, uniformly truly explanatory definition of the concept of terrorism. Therefore, all acts of violence directed against society are often assigned to terrorism across the board, without taking a closer look at and differentiating between the shareholders behind them, such as anti-government dissidents, organized gangs, or even individual perpetrators.

Moreover, in public usage, the term takes on an expanded meaning, referring both to the specific terrorist act itself and a state of terror and, thus, to numerous circumstances associated with intense fear or extreme anxiety (Aly \& Green, 2010). Moreover, the terrorism designation, at its core, represents a term used invariably as an attribution. Accordingly, it is not a neutral designation of a specific phenomenon but a (negative) evaluation of specific scenarios (Baecker et al., 2011).

Terrorist activities and other threat situations are increasingly becoming the focus of media attention, primarily due to digital communication possibilities, and reach the directly affected groups of people and far-flung segments of the population. One consequence of this omnipresence of terrorist acts or also the omnipresent awareness concerning the threat of such attacks is the fact that the fear of terrorism, but also the assessed risk of becoming a victim of such an attack oneself, represents an increasingly present concern in people's minds (Nellis \& Savage, 2012). According to Fischer et al. (2007), this phenomenon, described by numerous authors as terror salience as a possible construct before or in the course of various events, influences personal actions through increased security behavior and leads to effects concerning social coexistence. The authors were able to show that an increased sensitivity toward terrorist attacks or also general threat scenarios leads to a harsher individual judgment toward violations of criminal laws, even if the specific acts are not related to the phenomenon of terrorism. Thus, risk scenarios represent a form of threat to the social order, which both society and the individual try to compensate.

As a fundamental part of the review work, the inter- and intra-individual effects during specific threat scenarios focusing on terrorist activities will be discussed. It can and must be emphasized that concerning the impacts of diverse threat scenarios, psychotraumatology and the teaching of psychological trauma consequences are often the focus of research considerations. Various events are referred to as psychological injuries in the case of insufficient processing, which can develop into post-traumatic stress disorder (PTSD) and, thus, result in persistent feelings of dejection, deep despair, hopelessness, and even suicidal tendencies (Ehlers \& Clark, 2000). A construct to be distinguished from this disorder of directly or indirectly experienced traumatic events is the acute stress reaction. This shortterm reaction aimed at securing one's survival, which is often also described as a normal reaction to abnormal events, does not lead to lasting, but only temporary (clinical criterion: symptoms up to three months) impairments, in contrast to full-blown PTSD (Bengel \& Hubert, 2009). Due to the large amount of existing literature focusing on mental disorders as a 
consequence of traumatic experiences, the existence and, in part, the prevalence of these disorders in the context of the scenarios considered will undoubtedly be referred to in the present work, but they will not be further specified.

Intra- and interindividual patterns of experience, behavior, and action. Concerning emotional and cognitive processing patterns, former research can observe severe effects of directly or indirectly experienced terror and other threat events. After the terrorist attacks of September 11, 2001, Fredrickson et al. (2003) reported prevalent feelings of fear, anger, anxiety, and sadness, which could be detected as persistent effects even months after the attacks. The authors were able to show as a further psychological consequence a threat to the personal sense of security of the American. It becomes clear that the affective mood, in particular, represents a psychological construct that is directly negatively impaired due to any threat situations (Fischer et al., 2006; Kaiser et al., 2004). This can also influence mental health as a consequence of substantial impairment (Ai et al., 2005; Silver et al., 2002). A change in risk-taking towards increased caution was also observed by López-Rousseau (2005) due to terrorist attacks. The author focused his work on the percentage variations present in Spain during one year in terms of train trips taken and general traffic volume after the September 11 attacks and was able to show a significant decrease in these.

An analysis by Norris et al. (2002), who examined the effects of different types of disasters (e.g., technological or natural disasters, mass violence), was able to show that well-being and mental health are most negatively affected by mass violence such as terrorism compared to technical and natural threats as well as completed disasters. This finding is also emphasized by the previously noted study by Fredrickson et al. (2003) concerning the emotions reported by the U.S. population and, thus, the affective consequences of the devastating terrorist attack on the World Trade Center, which also highlights post-traumatic stress symptoms that were still evident months and years after the attacks (cf. also Brackbill et al., 2009, Silver et al., 2002). Since the attacks on the world-famous Twin Towers are among the most well-known terrorist events in world history (Comfort \& Kapacu, 2006), many scientific studies focus on psychological effects have been conducted, especially about this event. Among these, numerous studies (e.g., Galea et al., 2002; Schlenger et al., 2002) report significantly increased prevalence rates of PTSD in particular. In this regard, Perrin et al. (2007) particularly emphasize the mental health of the rescue and recovery workers involved on September 11 and found a likely PTSD rate of $7.2 \%$ among these occupational groups compared to the overall PTSD rate of $4 \%$ in the United States before the attacks. Thus, for the U.S. population, a large body of evidence indicates that direct and indirect exposure to the terrorist attacks has resulted in a long-term impairment of affective states. Due to the already emphasized increase in terrorist attacks in Europe, we can and must assume a similar reaction pattern of the European population regarding such events (Bowler et al., 2010). However, it should be noted in the context of these considerations that in the course of social science as well as psychological crisis and disaster research, it is assumed that the emotional, as well as behavioral reactions to diverse threats are dependent on the type, content, and overall 
assessment of precisely these threat(s) and, thus, no blanket statements can be made (Bock, 2017).

A threat to physical safety as one of the most fundamental threats is often accompanied by a sense of fear and an additional attempt to avoid the specific situation(s) (Cottrell \& Neuberg, 2005). Experienced fear in such a case can vary by the degree of subjectively assessed control: in particular, a professional lack of power in these same situations leads to increased fear and avoidance responses (Kamans et al., 2011).

Anger is also a frequently observed emotional state in the context of various threats. This emotion, which occurs when one's own goals are hindered, or even specific events are incompatible with one's motives (Roseman, 2001; Smith \& Lazarus, 1993), results in the context of any threat scenarios when economic resources and, thus, personal property appear threatened. However, in combination with the already noted and quite relevant feeling of control or even experienced powerlessness, people in this context can also experience additional anxiety in such situations associated with anger (Mackie et al., 2000). Overall, anger and fear represent the two most common emotional reactions to threat problems, which in summary depend on the type of threat as well as the evaluation of one's possibilities and the perceived power in the specific conditions (Kamans et al. 2011). While fear is associated with avoidance and securing physical and mental integrity, anger represents a more offensive action. In emotion research, it is also assigned to approach emotions (Frijda et al., 1989; Smith, 1993; Mackie et al., 2000). According to authors Cottrell and Neuberg (2005), in the context of specific crisis, disaster, or even terror situations, anger can only be considered meaningful if the removal of prevailing obstacles and the achievement of personal goals (and resources) is seen as possible.

To illustrate the impact of these emotional states in specific threat scenarios, we refer to Drury et al. (2009) research. The authors studied individual (mass) behavior on subway trains after the London bombings (2005). They were able to show, based on semi-structured interviews with survivors of various emergency or disaster events, that specific behavioral patterns can be observed in situations that can be classified as so-called mass panic. Mass panic is understood to mean that a particular group of people affected by extraordinary events is driven in its behavior more strongly by simple emotions than would the single individual in the given situation (Pastel, 2001). In the studies described, the authors were able to show that affected individuals generally either act in terms of psychosocial vulnerability or exhibit behaviors that are collectively attributed to collective resilience. In this context, psychosocial vulnerability represents a psychological construct that egoistic behaviors and, thus, predominant self-centeredness can characterize. Forming a unit or a permanently existing mutual help can express the partially reported cohesion. According to Strauss (1944), the former and consistently emotion-driven behavior of self-centeredness is attributed to personal survival threats and a prevailing sense of fear. The general socialization instinct is overwhelmed, and collective bonds are extinguished. 
Terror Management Theory (TMT). A classical approach concerning the experience, behavior, and action both before, during, and after any threat scenarios is the so-called Terror Management Theory (TMT) by Greenberg et al. (1986). The theory, which focuses on the typically evolving response patterns (management) in dealing with a fear of death (terror) and is considered one of the most prominent theories in social psychology (Burke et al., 2010), thinks the fear of one's mortality as an underlying factor in all behavior. It is assumed that due to cultural worldview (e.g., social norms, hope for immortality, striving for transcendence) and self-worth, which is referred to as the emotional level of self-preservation in the course of the theory, a social consensus and, confirmation by other individuals is needed in various threat scenarios and is often brought about by specific behaviors. Consequently, in situations where one's world view appears to be threatened, negative evaluations of persons who do not (seem to) share one's value convictions occur and are assigned to the so-called outgroup. The negative assessments are often clarified and reinforced by corresponding actions. According to TMT, in situations characterized by a so-called mortality salience, the need to defend one's cultural view of the world and, thus, fend off strangers who are experienced as threatening becomes apparent.

Overall, TMT assumes that human consciousness creates a specific potential to protect itself from a psychological threat during an experienced confrontation with dire circumstances. The theory distinguishes between threat-focused (proximal) attempts to remove concretely prevailing thoughts, often related to one's vulnerability, from consciousness and symbolic (distal) defense mechanisms aimed at coping with the not directly conscious resonance of death-related cognitions (Pyszcsynski et al., 1999). Accordingly, the proximal defense mechanisms mentioned first attempt to counter stressful events with cognitive solution approaches, resulting in reducing the subjective threat. On the other hand, distal defense mechanisms aim to achieve psychological protection via symbolic concepts of the self within a cultural context that is considered meaningful (Greenberg et al., 2008). Concerning the terrorist attacks of September 11, a reaction attributable to the distal defense mechanisms of TMT was demonstrated by increased support for the American president on the part of conservative Americans, who thereby attempted to defend their worldview and self-worth, which have been referred to as cultural fear buffers (Landau et al., 2004). TMT appears to be fundamental as a possible explanation of unique ways of experiencing, behaving, and acting in terms of understanding the human dimensions in dealing with diverse threat scenarios.

(Psycho)Physiological approaches. Findings on the psychological constructs already described during various threat situations often refer to physiological stress models in addition to retrospective reports from directly affected individuals. However, the previous findings should be prefaced that the human response pattern in emergencies is neither wholly predictable nor manipulable. Nevertheless, stress reactions can usually be identified when various crisis scenarios occur, which previous research approaches allow conclusions to be drawn about a possible subsequent reaction pattern. It should also be pointed out that human 
reaction behavior and the complexity and dynamics of the respective situations are key success and failure factors in dealing with threats and disasters.

Concerning the physiological aspects that significantly influence and control subsequent experience, behavior, and action, a general distinction is made between two cross-cultural levels of perception (e.g., Skinner \& Brewer, 2002): The fast and often unconscious perception, which on the one hand can lead to a startle and orientation reaction, but also flight and defense impulses, is an automatic emergency reaction, which can lead to an outward or also inward-directed flight or even to an attack. These reaction patterns can be observed, especially in situations that seem to be unpredictable and, therefore, uncontrollable. The slow and conscious perception is characterized by a mental assessment and an emotional evaluation about a possibly prevailing control of the current situation. However, stress reactions are also possible with this type of perception. This distinction of the differentiating levels of perception represents a merely basic human behavior approach in stress reactions.

Contrasted with this physiological approach, the so-called Terror Management Health Model (TMHM) by Goldenberg and Arndt (2008) represents a more specific and exemplified psychophysiological approach about behavior specifically focused on health in threat scenarios. Through this model, the authors seek to extend the TMT, which has already been specified in more detail, to decisions that people make concerning their physiological and psychological health. Thus, according to the model, health-oriented motivations, such as proximal defenses, serve to remove a present health threat from attention and awareness, whereas distal guards, as self-oriented motivations, aim to protect the value integrity of the self. Thus, in light of the information on TMT already elaborated, the TMHM postulates overall that in threatening situations, direct awareness of one's vulnerability leads to the promotion of health-oriented motivations. Decisions regarding one's integrity in cases that are not characterized by an acute threat make corresponding decisions guided only by self-referential reasons. As a basis for these reaction patterns, the already noted affective components of threatening situations can be listed, connected with the perceived controllability of specific conditions leading to corresponding impulses.

Through the approaches now presented briefly, the close entanglement between physical and psychological components becomes clear. Thus, while biological measures may well lead to corresponding behaviors, they are also influenced by their interaction with basic psychological constructs. Therefore, the theories and approaches presented so far make it clear that the experience, behavior, and action both before, during, and after various threat events require more specific consideration, focusing on the different levels of these reaction patterns.

\section{Implications}

This overview paper represents an attempt to provide an initial overview of the human experience, behavior and action in crises, disasters and, thus, also situations characterized by terrorism against the background of increasing threat scenarios. Overall, it becomes clear that 
a multitude of diverse factors exist, which must be taken into account with regard to the reaction pattern during, the effects after, or even the general awareness of specific threats. In addition to the often focused psychological sequelae, basic reaction patterns should and must be considered and further specified in order to be able to make statements about the individual as well as societal aspects with regard to the specified events in the future.

The results make clear that with regard to terrorist events not only a direct experience and, thus, participation is necessary to show a possibly also strongly pronounced psychophysiological reaction pattern, but that even an increased sensitivity and the sole awareness of the existence of possible threats seems sufficient for such consequences. Furthermore, it must be emphasized that dealing with threatening situations is not a matter of simple stimulus-response sequences, but that the respective experience, behavior, and action are influenced by numerous cognitive control processes. For example, successful escape alone relies on the integration of numerous external and internal variables and is considered only one, not always possible, behavioral response to confront crises and disasters (Evans et al., 2019). The present work could also address a classical approach in confronting one's mortality. For example, TMT, coined by Greenberg et al. (1986), attempts to explain human experience and behavior in threat scenarios as upholding and also defending one's values and norms.

Limitations. In terms of quantitative research, the intent of this review is to provide a secondary synthesis of existing knowledge and, to that end, to include a variety of methods, human circumstances, and experiences. It should be noted that the studies and findings included in this review have used different methodological approaches. The data come from individuals who have been in different situations, faced different circumstances, and been exposed to differentiating cultural environments. The differing analytical approaches and theoretical perspectives, as well as the use of sometimes small and selective samples, must also be emphasized at this point. It is recommended that further quantification of experience, behavior, and action in threat and terror scenarios be pursued and, for example, that motivational and psychophysiological activities also be included in the closer considerations.

In further studies, special attention should also be paid to the often-neglected distinction between direct victims of terrorist attacks and emergency personnel (e.g., police, firefighters, paramedics) or military organizations that find themselves in corresponding operational situations due to their professional qualifications. Especially concerning the acknowledged and thus inevitable involvement of the latter group of persons, findings on these persons' experience, behavior, and actions should focus on future research.

Implications for future research. In the context of diverse threat scenarios, one area that will necessarily require more specific consideration in future research is critical infrastructure. The facilities or even systems designated by this term, which are essential for maintaining critical societal functions of health, safety, and economic or social well-being of the population (Trump et al., 2017), are to be classified as particularly vulnerable structures, 
especially against the backdrop of terrorist activities (Yusta et al., 2011). Due to the great need for national and international action to protect these infrastructures, further findings on the experience, behavior, and activity in the context of diverse threat scenarios under these partly particular circumstances appear to be of fundamental importance concerning the development of specific instructions for action or also general tactical measures.

Conclusion. Bringing together findings from the literature discussed and the theoretical frameworks show that fundamental theories and approaches exist about the possible effects of diverse threat scenarios on human experience, behavior, and action. It becomes clear that in addition to the psychological components, disaster research must also consider physiological measures in the context of social science. These influence and control human response patterns both before, during, and after diverse events. However, the direct collection and analysis of individual data from real events is complicated and must also be considered critical concerning ethical principles and has rarely been attempted. Thus, the findings to date are primarily based on both retrospective reports and psychophysiological models.

Bringing together previous findings makes it clear that individual and societal experience, behavior, and action in as well as specific events represent a complex interplay of various factors and should be studied with a focus on the more typical circumstances of critical infrastructures in addition to previous approaches.

Acknowledgments. The authors would like to thank the Austrian funding program in the field of safety research (FFG KIRAS) and especially the consortium of the NIKE-SubMoveCon project (Sustainable Interdisciplinarity in Complex Underground Operations - Subsurface Movement Control) for advice, conception, and theoretical support and emphasize the relevance of these for the development of the paper.

FFG-Nr. 879720, Partner: Joanneum Research, Forschungsgesellschaft mbH, Montanuniversität Leoben, Ingenieurbüro Laabmayr \& Partner, IFR - Ing. Richard Feischl, Experience Research \& Consulting, Bundesministerium für Landesverteidigung, ASB Stmk

\section{References}

[1] Ai, A. L., Cascio, T., Santangelo, L. K., \& Evans-Campbell, T. (2005). Hope, meaning, and growth following the September 11, 2001, terrorist attacks. Journal of Interpersonal Violence, 20(5), 523-548.

[2] Aly, A., \& Green, L. (2010). Fear, anxiety and the state of terror. Studies in Conflict \& Terrorism, 33(3), 268-281

[3] Baecker, D., Krieg, P., \& Simon, F. B. (Eds.). (2011). Terror im System: der 11. September 2001 und die Folgen. Carl-Auer Verlag.

[4] Bengel, J., \& Hubert, S. (2009). Anpassungsstörung und akute Belastungsreaktion (Vol. 39). Hogrefe Verlag.

[5] Besley, T., Coelho, M., \& Van Reenen, J. (2013). Investing for prosperity: skills, infrastructure and innovation. National Institute Economic Review, 224(1), R1R13. 
[6] Bock, A. M. (2017). Islamistischer Terrorismus: Die konstruierte Bedrohung. Zeitschrift für Außen-und Sicherheitspolitik, 10(2), 245-265.

[7] Bowler, R. M., Han, H., Gocheva, V., Nakagawa, S., Alper, H., DiGrande, L., \& Cone, J. E. (2010). Gender differences in probable posttraumatic stress disorder among police responders to the 2001 World Trade Center terrorist attack. American journal of industrial medicine, 53(12), 1186-1196.

[8] Brackbill, R. M., Hadler, J. L., DiGrande, L., Ekenga, C. C., Farfel, M. R., Friedman, S., ... \& Thorpe, L. E. (2009). Asthma and posttraumatic stress symptoms 5 to 6 years following exposure to the World Trade Center terrorist attack. Jama, 302(5), 502516.

[9] Broadberry, S., \& Wallis, J. J. (2017). Growing, shrinking, and long run economic performance: Historical perspectives on economic development (No. w23343). National Bureau of Economic Research.

[10] Comfort, L. K., \& Kapucu, N. (2006). Inter-organizational coordination in extreme events: The World Trade Center attacks, September 11, 2001. Natural hazards, 39(2), 309-327.

[11] Cottrell, C. A., \& Neuberg, S. L. (2005). Different emo- tional reactions to different groups: A sociofunc- tional threat-based approach to "prejudice". Journal of Personality and Social Psychology, 88, 770-789.

[12] Creswell, J. W., \& Poth, C. N. (2016). Qualitative inquiry and research design: Choosing among five approaches. Sage publications.

[13] Drury, J., Cocking, C., \& Reicher, S. (2009). The nature of collective resilience: Survivor reactions to the 2005 London bombings. International Journal of Mass Emergencies and Disasters, 27(1), 66-95.

[14] Ehlers, A., \& Clark, D. M. (2000). A cognitive model of posttraumatic stress disorder. Behaviour research and therapy, 38(4), 319-345.

[15] Evans, D. A., Stempel, A. V., Vale, R., \& Branco, T. (2019). Cognitive control of escape behaviour. Trends in cognitive sciences, 23(4), 334-348.

[16] Fischer, P., Greitemeyer, T., Kastenmüller, A., Frey, D., \& Oßwald, S. (2007). Terror salience and punishment: Does terror salience induce threat to social order? Journal of Experimental Social Psychology, 43(6), 964-971.

[17] Fischer, P., Greitemeyer, T., Kastenmüller, A., Jonas, E., \& Frey, D. (2006). Coping with terrorism: The impact of increased salience of terrorism on mood and selfefficacy of intrinsically religious and nonreligious people. Personality and Social Psychology Bulletin, 32(3), 365-377.

[18] Fredrickson, B. L., Tugade, M. M., Waugh, C. E., \& Larkin, G. R. (2003). What good are positive emotions in crisis? A prospective study of resilience and emotions following the terrorist attacks on the United States on September 11th, 2001. Journal of personality and social psychology, 84(2), 365.

[19] Frijda, N. H., Kuipers, P., \& Ter Schure, E. (1989). Relations among emotion, appraisal, and emotional action readiness. Journal of Personality and Social Psychology, 57, 212-228.

[20] Galea, S., Ahern, J., Resnick, H., Kilpatrick, D., Bucuvalas, M., Gold, J., \& Vlahov, D. (2002). Psychological sequelae of the September 11 terrorist attacks in New York City. New England journal of medicine, 346(13), 982-987. 
[21] Greenberg, J., Solomon, S., \& Arndt, J. (2008). A basic but uniquely human motivation: Terror management.In J. Y. Shah \& W. L. Gardner (Eds.), Handbook of motivation science (p. 114-134). The Guilford Press.

[22] Hegemann, H., \& Kahl, M. (2018). Was ist Terrorismus? Eine schwierige Begriffsbestimmung. In Terrorismus und Terrorismusbekämpfung (pp. 9-27). Springer VS, Wiesbaden.

[23] Hoffman, B. (2001). Terrorismus. Der unerklärte Krieg. Frankfurt am Main.

[24] Homer-Dixon, T. (2002). The rise of complex terrorism. Foreign Policy, (128), 52.

[25] Juergensmeyer, M. (2017). Terror in the mind of God: The global rise of religious violence (Vol. 13). Univ of California Press.

[26] Kaiser, C. R., Vick, S. B., \& Major, B. (2004). A prospective investigation of the relationship between just-world beliefs and the desire for revenge after September 11, 2001. Psychological Science, 15(7), 503-506.

[27] Kamans, E., Otten, S., \& Gordijn, E. H. (2011). Power and threat in intergroup conflict: How emotional and behavioral responses depend on amount and content of threat. Group Processes \& Intergroup Relations, 14(3), 293-310.

[28] Kressel, N. (2008). Mass hate: The global rise of genocide and terror. Hachette UK.

[29] Landau, M. J., Solomon, S., Greenberg, J., Cohen, F., Pyszczynski, T., Arndt, J., ... \& Cook, A. (2004). Deliver us from evil: The effects of mortality salience and reminders of $9 / 11$ on support for President George W. Bush. Personality and Social Psychology Bulletin, 30(9), 1136-1150.

[30] Lauwe, P., \& Riegel, C. (2008). Schutz Kritischer Infrastrukturen-Konzepte zur Versorgungssicherheit. Informationen zur Raumentwicklung, (1-2), 113-125.

[31] Lerner, J. S., Gonzalez, R. M., Small, D. A., \& Fischhoff, B. (2003). Effects of fear and anger on perceived risks of terrorism: A national field experiment. Psychological science, 14(2), 144-150.

[32] López-Rousseau, A. (2005). Avoiding the death risk of avoiding a dread risk: The aftermath of March 11 in Spain. Psychological Science, 16(6), 426-428.

[33] Mackie, D. M., Devos, T., \& Smith, E. R. (2000). Intergroup emotions: Explaining offensive action tendencies in an intergroup context. Journal of Personality and Social Psychology, 79, 602-616.

[34] Nellis, A. M., \& Savage, J. (2012). Does watching the news affect fear of terrorism? The importance of media exposure on terrorism fear. Crime \& Delinquency, 58(5), 748-768.

[35] Norris, F. H., Friedman, M. J., \& Watson, P. J. (2002). 60,000 disaster victims speak: Part II. Summary and implications of the disaster mental health research. Psychiatry, 65, 240-260.

[36] Pastel, R. H. (2001). Collective behaviors: mass panic and outbreaks of multiple unexplained symptoms. Military Medicine, 166(suppl_2), 44-46.

[37] Perrin, M. A., DiGrande, L., Wheeler, K., Thorpe, L., Farfel, M., \& Brackbill, R. (2007). Differences in PTSD prevalence and associated risk factors among World Trade Center disaster rescue and recovery workers. American Journal of Psychiatry, 164(9), 1385-1394.

[38] Pyszczynski, T., Greenberg, J., \& Solomon, S. (1999). A dual-process model of defense against conscious and unconscious death-related thoughts: an extension of terror management theory. Psychological review, 106(4), 835. 
[39] Roseman, I. J. (2001). A model of appraisal in the emotion system: Integrating theory, research, and applications. In K. R. Scherer, A. Schorr, \& T. Johnstone (Eds.), Appraisal processes in emotion: Theory, methods, research (pp. 68-92). London: Oxford University Press.

[40] Schlenger, W. E., Caddell, J. M., Ebert, L., Jordan, B. K., Rourke, K. M., Wilson, D., ... \& Kulka, R. A. (2002). Psychological reactions to terrorist attacks: findings from the National Study of Americans' Reactions to September 11. Jama, 288(5), 581-588.

[41] Silver, R. C., Holman, E. A., McIntosh, D. N., Poulin, M., \& Gil-Rivas, V. (2002). Nationwide longitudinal study of psychological responses to September 11. Jama, 288(10), 1235-1244.

[42] Skinner, N., \& Brewer, N. (2002). The dynamics of threat and challenge appraisals prior to stressful achievement events. Journal of personality and social psychology, 83(3), 678.

[43] Smith, C. A., \& Lazarus, R. S. (1993). Appraisal com- ponents, core relational themes, and emotions. Cognition \& Emotion, 7, 233-269.

[44] Smith, E. R. (1993). Social identity and social emotions: Toward new conceptualizations of prejudice. In D. M. Mackie \& D. L. Hamilton (Eds.), Affect, cognition, and stereotyping: Interactive processes in group perception (pp. 297315). San Diego, CA: Academic Press.

[45] Strauss, A. L. (1944). The literature on panic. The Journal of Abnormal and Social Psychology, 39(3), 317.

[46] Thiele, R. (2009). Trendforschung und die Entwicklung von Konfliktbildern in der Bundeswehr. Zeitschrift für Außen-und Sicherheitspolitik, 2(2), 147-157.

[47] Trump, B. D., Poinsatte-Jones, K., Elran, M., Allen, C., Srdjevic, B., Merad, M., ... \& Palma-Oliveira, J. M. (2017). Social resilience and critical infrastructure systems. In Resilience and risk (pp. 289-299). Springer, Dordrecht.

[48] Yusta, J. M., Correa, G. J., \& Lacal-Arántegui, R. (2011). Methodologies and applications for critical infrastructure protection: State-of-the-art. Energy policy, 39(10), 6100-6119. 